\title{
Educação para saúde por meio de processos dialógicos e o autocuidado da pessoa surda
}

\author{
Health education through dialogue processes, and the self-care \\ of the deaf individual
}

Fabiana Scassiotti Fernandes Solia ${ }^{1}$. Silvia Sidnéia da Silva ${ }^{2}$

\begin{abstract}
Resumo: Estudo qualitativo que, por meio de uma pesquisa-ação, objetivou avaliar a efetividade dos processos dialógicos em Língua de Sinais, na educação para saúde, visando ao autocuidado de adolescentes surdos. Para a coleta de dados, realizaram-se entrevistas semiestruturadas, com cinco adolescentes surdos de um município do sul de Minas Gerais. A análise dos dados se deu por categorização em um diálogo com Paulo Freire. Os resultados apontaram a falta de autonomia e consciência das ações para o autocuidado. Na ação educativa, feita por meio das Rodas Dialógicas, constatou-se a motivação dos adolescentes surdos a (inter)agirem e refletirem sobre os significados da mudança no status e na prática de receptores a construtores de conhecimentos para o autocuidado. Concluindo, verificou-se a necessidade da mobilização na busca de novas práticas e fazeres visando à formação de cidadãos autônomos e responsáveis por sua saúde, considerando as peculiaridades linguísticas da pessoa surda.
\end{abstract}

Palavras-chave: Educação para a saúde. Autocuidado. Surdez. Deficiência auditiva. Língua Brasileira de Sinais.

\begin{abstract}
This qualitative study through action research, aimed to evaluate the effectiveness of dialogic processes in Sign Language, in health education, promoting the self-care of deaf adolescents. For the data collection, semi-structured interviews were held, with five deaf adolescents from a city in the south of Minas Gerais state. The data analysis was done through categorization using the influence of Paulo Freire. The results showed the lack of autonomy and awareness of actions for the self-care. In the educational action performed by the Dialogue Circles, it was found that deaf adolescents were motivated to interact and reflect on the meaning of status quo changes and about the roles of receptors and constructors of knowledge on self-care. In conclusion there is need motivating students to form new habits aiming at the formation of autonomous citizens, responsible for their own health, and taking into account their language singularities as a deaf person.
\end{abstract}

Keywords: Education for health. Self-care. Deafness. Hearing impairment. Brazilian Sign Language.

\footnotetext{
${ }^{1}$ Universidade do Estado de Minas Gerais, Faculdade de Educação, Poços de Caldas, MG, Brasil. E-mail:

$<$ fascasol@yahoo.com.br>.

${ }^{2}$ Universidade de Ribeirão Preto, Ribeirão Preto, SP, Brasil.
} 


\section{Introdução}

Sabe-se que o governo brasileiro está se empenhando cada vez mais para a conscientização, divulgação e concretização da inclusão de todos os brasileiros nas práticas sociais, e essa postura está exigindo que os sistemas de ensino e de saúde se adaptem e se reestruturem para receber todas as pessoas, considerando suas especificidades.

No que tange à pessoa surda, ressaltamos que neste estudo adotamos a visão de surdez defendida por Sacks (1998), entendendo-a não como deficiência, mas como diferença linguística e cultural. Os sistemas de ensino e de saúde precisam buscar meios para colocar em prática a educação bilíngue, já garantida legalmente, para este público. Perlin (2014, p. 229) define a educação bilíngue sendo um "[...] método que leva a usar a língua dos sinais como primeira língua, ou seja, como língua de instrução e a língua portuguesa como segunda língua, com significâncias de língua estrangeira [...].”. Fernandes (2003) afirma que bilinguismo na educação não pode ser pensado de maneira simplista, sendo apenas a inclusão da Língua de Sinais, juntamente com a Língua Portuguesa na sala de aula, ou a mera tradução dos conteúdos pedagógicos para a Língua de Sinais, ela assevera a importância de considerar a totalidade do aluno em seu ambiente psicossociocultural.

A Língua Brasileira de Sinais (Libras) é uma língua reconhecida por meio da lei $\mathrm{n}^{\circ}$ 10.436/02 como meio legal de comunicação e expressão, regulamentada pelo decreto $n^{\circ} 5.626$ de 22 de dezembro de 2005 que, entre outras providências, trata do direito à educação bilíngue e à garantia do direito à saúde das pessoas surdas ou com deficiência auditiva.

O capítulo VII do decreto supracitado trata especificamente dessa garantia e traz, em seu artigo 25, que o Sistema Único de Saúde (SUS) deve garantir, prioritariamente, aos alunos matriculados nas redes básicas de ensino, a atenção integral à sua saúde. No inciso II, o documento afirma que o tratamento clínico e o atendimento especializado devem ocorrer respeitando as especificidades de cada caso; o inciso VIII aborda a orientação à família sobre implicações da surdez e sobre a importância do acesso a Língua de Sinais e Língua Portuguesa, desde o nascimento. Já o inciso IX preconiza o atendimento às pessoas surdas na rede de serviço do SUS por profissionais capacitados para o uso de Libras ou para a sua tradução e interpretação.

No Brasil, efetivar a educação bilíngue para os surdos não é algo simples, especialmente nas cidades do interior. Lacerda, Albres e Drago (2013) afirmam que a educação de surdos ainda é um tema polêmico e nem todo resultado é positivo.

Deve-se observar que "as experiências com educação bilíngue ainda são restritas a alguns centros, dadas as dificuldades de implantação de uma proposta nova que envolva pessoas surdas e ouvintes com domínio de LIBRAS” (LACERDA, 2000, p. 54). Ainda sobre educação bilíngue, a autora comenta que "[...] não basta um decreto para uma transformação efetiva das práticas. A legislação pode induzir ações, mas elas só serão eficazes se de fato a condição linguística especial do surdo for compreendida e ações para a criação de uma efetiva escola bilíngue forem implementadas” (LACERDA, 2009, p. 27).

Lacerda, Albres e Drago (2013, p. 77) afirmam que, "no Brasil, a atuação do intérprete de língua de sinais no cenário escolar é recente e ainda indagam sobre sua formação, suas práticas e a realidade que vivencia na escola".

Assim, não se pode pensar, nacionalmente, em um atendimento bilíngue em todos os municípios, nas escolas e no Sistema Único de Saúde, pois muitas cidades do país não contam 
com o profissional bilíngue ou com um tradutor - intérprete das Línguas em questão - para atender às reais necessidades das pessoas surdas, na rede regular de ensino e na rede pública de saúde. Esses sistemas precisam partir de suas realidades para buscar efetivar o que é garantido constitucionalmente para todos os cidadãos brasileiros, desde 1988: a educação e a saúde como direito de todos.

Apesar de as pessoas surdas já contarem com a garantia legal da presença desses profissionais nos setores públicos, há que se somarem esforços para a formação desses indivíduos na direção da concretização desse direito. E, consoante com o inciso X do artigo 25 do decreto 5.626, de 22 de dezembro de 2005, o SUS e as empresas que detêm concessão ou permissão dos serviços públicos de assistência à saúde devem apoiar a capacitação e a formação de profissionais da rede de serviços do SUS, tanto para o uso da Libras quanto para a tradução/interpretação das línguas envolvidas. Ainda o Parágrafo 1. ${ }^{\circ}$ do Artigo 26, do Capítulo VIII assegura que essas instituições devem dispor de, no mínimo, $5 \%$ de seus servidores, funcionários e empregados capacitados para o uso e a interpretação da Libras.

De acordo com os Parâmetros Curriculares Nacionais (BRASIL, 1997, p. 85), “o ensino de Saúde tem sido um desafio para a educação, no que se refere à possibilidade de garantir uma aprendizagem efetiva e transformadora de atitudes e hábitos de vida". Também conforme os PCN, a Educação para Saúde, considerando o meio físico, social e cultural pode ser propulsora de melhorias da saúde individual e também da coletividade como estratégia de proteção, promoção e meio/fim para a construção e efetivação dos direitos de cidadania.

Nesse processo de construção de novos conhecimentos, o trabalho educativo deve promover trocas de saberes, considerando todas as informações e experiências que cada sujeito abarca sobre o tema para que, em um processo dialógico, haja o desenvolvimento da consciência crítica e o autoconhecimento nessa busca pela autonomia, pelo bem-estar e autocuidado.

No cenário citado anteriormente, é fundamental considerar as necessidades específicas e reais de cada sujeito, propondo-se uma aprendizagem significativa, e que por meio do diálogo propicie a transformação de saberes existentes, pois, afinal, "ensinar não é transferir conhecimento, mas criar as possibilidades para a sua própria produção ou a sua construção" (FREIRE, 1996, p. 47). A partir desse pensamento do educador Paulo Freire, infere-se que deve haver disponibilidade contínua para o diálogo, em um movimento dinâmico de transformação da realidade.

Objetivamos, nessa direção, avaliar a efetividade dos processos dialógicos em Língua Brasileira de Sinais, na educação para saúde, visando ao autocuidado de adolescentes surdos em um município do interior de Minas Gerais/Brasil, além de levantar os conhecimentos prévios dos adolescentes surdos sobre autocuidado e viabilizar/estimular reflexões sobre o conhecimento de hábitos saudáveis/autocuidado dos sujeitos envolvidos na pesquisa, estando com eles nas rodas dialógicas, em uma perspectiva educativa e de intervenção na busca de uma prática autônoma e responsável pela saúde individual.

Enfatiza-se no contexto deste estudo as ações de autocuidado, como colocado por Bub et al. (2006, p. 155):

Constituem a prática de atividades que os indivíduos desempenham de forma deliberada em seu próprio benefício com o propósito de manter a vida, a saúde e o bem-estar. Essas ações são voluntárias e intencionais, envolvem 
a tomada de decisões, e têm o propósito de contribuir de forma específica para a integridade estrutural o funcionamento e o desenvolvimento humano. Constituem a capacidade humana ou o poder de engajar-se no autocuidado.

Autocuidado, tendo como referencial os PCN (BRASIL, 1997, p. 106), refere-se a "conhecer-se e cuidar-se, valorizando sua identidade e características pessoais". A conscientização da importância do cuidar de si leva à autonomia e à busca do controle de vida, não mais ficando como dependente do outro, não mais projetando no outro a responsabilidade pelo cuidado. Sabemos que o autoconhecimento, além de fortalecer o sujeito, instrumentaliza-o para o enfrentamento dos problemas cotidianos. Freire (2014a, p. 44) pontua que "a consciência do mundo e a consciência de mim me fazem um ser não apenas no mundo, mas com o mundo e com os outros", e, assim, o homem não meramente se adapta, mas intervém no mundo se fazendo, constituindo-se e se tornando ser histórico. Intervir na realidade é uma tarefa complexa e gera novos saberes permitindo ao homem refletir sobre si dando sentido à sua presença no mundo.

Ao pensar os caminhos para o autocuidado, Camargo-Borges e Japur (2008, p. 66) pontuam que "há que se levar em conta a complexidade da realidade local e do cotidiano popular que faz das práticas do autocuidado algo mais complexo do que a simples adesão a um tratamento prescrito", favorecendo a mudança de postura, criticidade e a construção de conhecimentos e sentidos, promovendo, assim, uma interlocução entre os saberes popular e o científico, sem a tendência de julgar e hierarquizá-los.

A educação para Paulo Freire é um ato político com que os próprios educadores se reeducam; objetiva não somente um novo tipo de sociedade, mas "criar com o poder do saber do homem libertado, um homem novo, livre também de dentro para fora” (BRANDÃO, 1981, p. 87). Assim, tanto o educador como o educando devem ser autônomos no processo de educação para saúde, e não apenas reprodutores ou praticantes de uma ideologia imposta pelo sistema.

A preocupação com a ineficiência de tais práticas não é recente. Após o Ministério da Educação reconhecer que a abordagem por meio da transmissão de informações é incapaz de levar os alunos a desenvolverem hábitos de vida saudáveis, propõe, por meio dos PCN (BRASIL, 1997), que a educação para a saúde seja um tema transversal, que deverá permear todas as áreas do conhecimento que formam o currículo escolar do nosso país. Percebe a educação como uma das formas mais significativa para a promoção de saúde dentro do contexto real do educando, podendo o professor e a comunidade escolar contribuírem na formação de cidadãos críticos e reflexivos, com condições para atuar na busca de forma a concretizar melhorias na qualidade de vida e saúde, na esfera pessoal e coletiva.

O papel do professor é de grande importância e Freire (1996, p. 26) pontua que, "nas condições de verdadeira aprendizagem, os educandos vão se transformando em reais sujeitos da construção e da reconstrução do saber ensinado, ao lado do educador, igualmente sujeito do processo", que não apenas ensina o conteúdo, mas vai além, ensina a pensar certo. Assim, deve-se reconhecer que a educação para a saúde deve se dar de maneira contextualizada, partindo de cada sujeito e sua história, do seu espaço e tempo, valorizando a experiência sociocultural de cada pessoa.

Esta consciência sanitária, a busca por promoção e proteção à saúde deve ocorrer considerando que toda transformação se dá nas relações com o meio físico, social e cultural, em um determinado espaço e tempo. A promoção da saúde, nas palavras de Pelicioni e Pelicioni (2012, p. 65), "é o processo que permite à população exercer maior controle sobre os determinantes e 
condicionantes da saúde visando sua melhoria". A Educação e a Saúde juntas podem promover a consciência do reconhecimento de estilos e hábitos de vida saudáveis, bem como da produção de um ambiente saudável, em um trabalho coletivo, onde cada uma, com seus conhecimentos, coloque seus saberes em prol da população; utilizando a vertente de empoderamento, de despertar os sujeitos, que (re)constroem seus conhecimentos para a ação, assumindo a partir de um autoconhecimento, sua capacidade de agente transformador no âmbito individual e no coletivo.

Como apregoado por Freire e Shor (1986), o empoderamento está ligado à conscientização e ao diálogo e "indica um processo político das classes dominadas que buscam a própria liberdade da dominação, um longo processo histórico de que a educação é uma frente de luta" (FREIRE; SHOR, 1986, p. 72).

Pelicioni e Pelicioni (2012, p. 66) afirmam que a ação educativa deve "ser de comunicação e diálogo, pois somente motivado o indivíduo poderá incorporar novos significados e valores para melhorar sua saúde e qualidade de vida". De acordo com Horochoyski e Meireles (2007), sem o mínimo de empoderamento intrapessoal, impera um sentimento de derrota, e a motivação para participar ativamente de qualquer deliberação é fortemente reduzida.

A definição de empoderamento, para Horochovski e Meireles (2007, p. 486), "é próxima da noção de autonomia, pois se refere à capacidade de os indivíduos e grupos poderem decidir sobre as questões que lhes dizem respeito". Lembrando que, de acordo com Freire (1996), o desenvolvimento da autonomia se dá respeitando a liberdade, de maneira processual, com vivências de tomada de decisão e de responsabilidade e que o respeito à autonomia de cada sujeito é um imperativo ético e não algo que se pode ou não oferecer uns aos outros.

Nessa direção, a educação para a saúde pode colaborar na formação de cidadãos autônomos, dispostos a participarem livre e ativamente no SUS, em que, por uma consciência crítica, percebam-se como corresponsáveis por esse sistema, participando dos seus conselhos e das conferências de saúde, caminhando com o entendimento de saúde e democracia como nas bases do movimento da Reforma Sanitária.

Considerando o método de educação de Paulo Freire, a educação para a saúde pode provocar o cidadão, por meio da conscientização, de um processo de transformação do modo de pensar, de uma compreensão crítica, criativa e comprometida com a força na participação social.

Almeja-se, com a educação para a saúde, despertar em todos e em cada um, à sua maneira, a responsabilidade e a solidariedade na busca da saúde individual e coletiva, em sua dimensão pessoal e social. Para tanto, o educador em saúde precisa conhecer diferentes realidades para favorecer a promoção do desenvolvimento da consciência crítica, em busca do conhecimento que liberta e favorece o empoderamento dos sujeitos.

\section{Percurso metodológico}

Trata-se de estudo de cunho qualitativo que utilizou a pesquisa-ação. Thiollent (2012) ressalta os objetivos da pesquisa-ação como a identificação dos problemas e a busca de ações para a resolução, aumentando a consciência, os níveis de reflexão e o comprometimento dos participantes da pesquisa por meio de ações significativas, gerando informações e difundindo conhecimentos construídos pelos atores, sendo adequados para a solução dos problemas identificados no início do projeto. 
A pesquisa foi realizada em um município do interior de Minas Gerais, o locus foi um Centro Municipal de Atendimento Educacional especializado para surdos que conta com profissionais bilíngues e intérpretes de Libras, que trabalham fundamentados em uma proposta pautada na perspectiva bilíngue. Essa unidade oferece, em contraturno, o Atendimento Educacional Especializado, ofertando o ensino da Libras, o ensino em Libras e do Português como metodologia do ensino de segunda língua, além do atendimento fonoaudiológico. Desenvolve cursos para professores da rede regular e oficinas de Libras abertas aos familiares, professores e comunidade promovendo, inclusive, a colocação e o acompanhamento de pessoas surdas no mercado de trabalho.

Este estudo teve como participantes cinco adolescentes surdos, com idades entre $14 \mathrm{e}$ 17 anos, obedecendo aos limites cronológicos da adolescência, apresentados pela Organização Mundial da Saúde (OMS), que se constituiu referencial para este estudo.

O critério de inclusão explicitou que o participante devia ser adolescente surdo, com idades entre 10 e 19 anos, e se comunicar por meio da Língua Brasileira de Sinais, residir na cidade de Poços de Caldas (MG) e estar regularmente matriculado no Centro Municipal de Atendimento Educacional Especializado.

O instrumento dessa pesquisa foi elaborado pelas pesquisadoras, considerando a apropriação de bibliografias científicas disponíveis sobre o tema de estudo associada à experiência de prestação de serviços da pesquisadora às pessoas surdas e suas famílias, pois não foram encontrados na literatura quaisquer documentos testados, que atendessem ao propósito do presente estudo. O documento foi submetido à apreciação externa de experts da área do estudo. Também foi realizada a entrevista com adolescentes surdos não residentes no município de Poços de Caldas, excluídos do estudo, a fim de verificar a necessidade de adequação do roteiro.

O roteiro para a entrevista foi composto de dados de identificação, os conceitos de saúde, qualidade de vida, hábitos saudáveis e autocuidado. Cabe salientar que a pesquisadora conhecia a população que foi entrevistada e sua condição de usuária da Libras e tradutora/ intérprete de Língua de Sinais facilitou a escolha dos sinais utilizados durante a entrevista, permitindo uma interpretação contextualizada, de maneira simples e direta.

No estudo, foram resguardadas todas as condutas referentes à autorização ética e legal para a realização de pesquisas, presentes na Resolução 466/12. O Termo de Consentimento Livre e Esclarecido foi assinado pelo responsável, bem como o de Termo de Assentimento Livre Esclarecido, pelos menores de 18 anos. O estudo foi autorizado pelo Comitê de Ética em Pesquisa com Seres Humanos da Universidade de Ribeirão Preto, sob parecer n. ${ }^{\circ}$ 816.872, de 29 de outubro de 2014.

Inicialmente, para a coleta de dados, que ocorreu em dezembro de 2014, foram feitas entrevistas semiestruturadas, individuais, buscando conhecer quais os saberes que os adolescentes apresentavam sobre saúde e autocuidado, bem como a trajetória de aprendizagem e autonomia desses sujeitos.

A análise dos dados coletados nas entrevistas, expressos em Língua de Sinais e traduzidos para Língua Portuguesa, deu-se por categorização, em um diálogo com Paulo Freire na perspectiva da adaptação feita por Bueno (2001), contemplando: (a) levantamento do universo temático, compreendendo a descrição e interpretação da situação dos participantes da pesquisa, identificação de suas necessidades de aprendizagem e levantamento de seus conhecimentos prévios; e (b) desenvolvimento da proposta educativa da pesquisa-ação. 
Educação para saúde por meio de processos dialógicos e o autocuidado ...

Com a categorização foi possível levantar as experiências vividas, conhecimentos prévios, necessidades e os problemas emergentes que nortearam a ação educativa nas Rodas Dialógicas.

As Rodas Dialógicas foram planejadas após análise dos dados e levantamento dos temas geradores referentes ao autocuidado. Foram feitos quatro encontros, com duração de duas horas cada um, no salão do Centro Municipal de Atendimento Educacional Especializado para surdos, sendo três encontros no mês de março e um em abril de 2015.

Essas rodas tiveram como enfoque a educação em saúde por meio de processos dialógicos visando à autonomia em saúde e à responsabilidade pelo autocuidado. O olhar, durante os momentos de observação, foi orientado pelo aporte teórico de Paulo Freire, principalmente nos estudos voltados para os processos dialógicos e da educação libertadora, por oferecer respaldo para a intervenção a fim de favorecer a aprendizagem e, consequentemente, o desenvolvimento dos sujeitos da pesquisa.

A apresentação das análises para os sujeitos da pesquisa se deu a partir de encontros em que socializaram as reflexões. Para que esse momento fosse de ação-reflexão e transformação da práxis buscou-se, desde o início da pesquisa, estabelecer relações de confiança para uma construção coletiva de (re)significação das práticas e conhecimentos evidenciados, visando à transformação da realidade socialmente construída.

Posteriormente ao contato individual, realizaram-se as Rodas Dialógicas. Devido à dinâmica proposta no estudo, foram feitas gravações dos encontros coletivos em vídeo, para melhor compreensão das expectativas, atitudes, hábitos de vida saudáveis, bem como das negociações construídas e (re)significações, produzidas pelas interações e pelos diálogos, observando-se também as colocações das pessoas surdas, relações estabelecidas e vínculos formados entre elas, seus dizeres individuais e coletivos e as práticas vivenciadas, que também foram fontes para avaliação das Rodas Dialógicas.

As Rodas Dialógicas tiveram início pela abordagem do autoconhecimento. Esses momentos foram filmados e as enunciações se constituíram em objeto de fundamentação para a avaliação dos impactos dos processos dialógicos em Língua de Sinais, na educação para saúde, visando ao autocuidado dos adolescentes surdos. Posteriormente, foram feitas as interpretações dos dados coletados, pela pesquisadora, para a avaliação das Rodas Dialógicas, considerando a experiência e a capacidade para esse ato tradutório/interpretativo em Língua de Sinais e Língua Portuguesa.

A partir das oportunidades de interação e diálogo, a busca se pautou em conhecer melhor as concepções, expectativas e atitudes dessas pessoas e como elas se constituem, em meio à diversidade que compõe a rede de educação e saúde, e também os impactos das Rodas Dialógicas para a produção de sentido e para a (re)construção de conhecimentos, no que tange ao autocuidado e à saúde.

\section{Resultados e discussão}

Os participantes da pesquisa foram identificados por meio de letras. Foram entrevistados cinco adolescentes surdos, sendo um do gênero masculino e quatro do gênero feminino, com idades entre 14 e 17 anos, cursando do $7^{\circ}$ ano do Ensino Fundamental ao $2 .^{\circ}$ ano do Ensino 
Médio, todos com o sustento provido pelos responsáveis. Destes, dois são da religião católica, dois são evangélicos e um não soube relatar. Todos residem na zona urbana e não souberam referir sobre a renda familiar e dois não tinham informações sobre pessoas doentes na família. Apenas um participante teve a Língua Portuguesa como primeira Língua; os demais aprenderam a Língua de Sinais. Dentre os cinco participantes, não houve relatos de terem parentes com surdez, permitindo-nos inferir que os sujeitos da pesquisa são filhos de pais ouvintes, corroborando dados de Chaveiro (2011), quando afirma que a maioria dos surdos são filhos de pais ouvintes.

Nesse contexto, acreditamos que os desconhecimentos apontados se justificam pelo fato de não compartilharem da mesma modalidade de língua de seus pais. Esse achado vai ao encontro dos registros de Santana (2007), quando afirma que os surdos, filhos de pais ouvintes, não vivenciam muitas situações de uso da linguagem. Não havendo interação, os surdos ficam à margem do que se passa com a família.

Sacks (1998) ainda pontua que crianças surdas, filhas de pais ouvintes, sofrem uma alienação em suas próprias famílias.

Seguem as respostas categorizadas e discutidas, resultantes à pergunta referente ao entendimento sobre autocuidado e referente às ações para o autocuidado.

Autocuidado ligado à dependência de outros para o cuidado:

\author{
É minha mãe me dar remédio e eu tomar. [Sujeito A]. \\ Fažer tudo que a minha mãe fala. [Sujeito B]. \\ É obedecer à minha mãe. [Sujeito C].
}

Minha mãe me dar comida e as pessoas me ajudarem. [Sujeito D].

Minha mãe e minha vó que cuidam de mim. [Sujeito E].

Ressalta-se o fato de todos os adolescentes da pesquisa não se reconhecerem responsáveis e capazes para o autocuidado, tendo sempre a mãe como provedora de todos os cuidados. Demonstram adaptar-se, ajustar-se à realidade, recebendo "tudo pronto", sendo aqueles que recebem o que lhes falta, sem questionamento, ausência de autoconhecimento, sem saber o porquê das suas ações, sem autonomia e criticidade, apenas seguindo uma prescrição, com ações automatizadas. Há que se buscar nesses adolescentes a superação do sujeito espectador, rumo à formação do homem que, na interação com o outro, cria e transforma sua realidade.

Com as respostas dadas, percebemos que os entrevistados não agem em uma constante ação-reflexão-ação e transformação, mas perpetuam um fazer automático. Verificamos, novamente, frutos de uma educação bancária que, para Freire (2014b, p. 84), "juntam toda a ação social de caráter paternalista, em que os oprimidos recebem o nome simpático de assistidos". Assim, não é possível a conscientização destes, o desvelamento do seu mundo, do cuidar de si com autonomia, de se humanizar. Essas constatações nos atentaram para esta temática no planejamento da ação educativa que foi realizada.

Ao perguntarmos sobre as ações de autocuidado, todos os participantes atrelaram à dependência de outros para o cuidado. 
Educação para saúde por meio de processos dialógicos e o autocuidado ...

É a minha mãe que cuida de mim. Ah, eu tomo remédio. [Sujeito A].

Minha mãe cuida bem de mim. Ela é brava, mas cuida de mim. [Sujeito B].

Eu obedeço à minha mãe em tudo. [Sujeito C].

Mamãe que cuida de mim. Eu faço o que ela manda. [Sujeito D].

Minha mãe e vó que cuidam, elas me dão remédio. [Sujeito E].

Dos entrevistados, apenas um pontuou tomar remédio sozinho, não tendo referências sobre o que fazem para cuidarem de si. Os cinco participantes demonstraram dependência da mãe.

Nossa atenção se voltou para a falta de autonomia e consciência nas ações para o autocuidado, apresentadas pelos adolescentes desta pesquisa, visto que a ação, nas palavras de Freire (2014b, p. 55), "só é humana quando, mais que um puro fazer, é que fazer, isto é, quando também não se dicotomiza da reflexão". Dessa forma, reconhecemos a necessidade de dialogar com esses adolescentes surdos sobre sua ação e não de depositar em cada um comunicados referentes às ações para o autocuidado. Essa postura visou alimentar o poder criativo de cada adolescente surdo, bem como seu poder de atuar e de optar por hábitos saudáveis, em favor de si próprio; e não meramente, como apontado pelas palavras categorizadas, um armazenamento das narrações que os outros lhes fazem.

\section{Ação Educativa: Rodas Dialógicas}

Com esta pesquisa-ação, foi possível desenvolver, junto aos alunos surdos, Rodas Dialógicas abordando questões sobre o autocuidado, com vistas ao empoderamento do grupo e de cada indivíduo, apontando o autocuidado em saúde e os preparando para serem multiplicadores desses saberes.

Antes da abordagem sobre o tema central, foram levantados o autoconhecimento e a saúde integral na primeira e segunda rodas, respectivamente. Na terceira, considerando o despertar para um maior conhecimento de si mesmo, e uma visão ampliada de saúde construída por todos os envolvidos, adentramos na elaboração do conceito de autocuidado, dialogando sobre as maneiras que cada um poderia cuidar de si no dia a dia, ainda perpassamos por temas como hábitos nocivos e hábitos saudáveis, alimentação, exercícios físicos, higiene e estresse.

Primeiramente, os adolescentes pontuaram que suas mães alertavam sobre alimentação saudável e higiene. Durante o debate, foi possível verificar que agem, muitas vezes, sem saber o porquê, fato já levantado durante as entrevistas. Tratamos também da importância do acesso às diversas fontes de informação sobre saúde e autocuidado, na perspectiva do conhecimento enquanto meio para autonomia.

Visando à tomada de consciência crítica, propusemos aos adolescentes um brainstorm, apresentando 25 fichas com imagens, representando saúde e ausência desta, sugerindo que deveriam discutir/debater como cuidar de si no contexto da imagem apresentada. De imediato, alocaram os cuidados recebidos pelas mães, mas foi proposto que se imaginassem em uma si- 
tuação e lugar onde seria impossível contar com os cuidados delas, sendo cada um responsável por cuidar de si.

Nesse momento, vivendo o novo cenário, imperou a fala referente a serem surdos e não encontrarem pessoas com domínio da Libras, nos diversos espaços da sociedade. Foram instigados a pensarem em soluções, em meios para saírem da passividade e superarem a condição de vítimas para assumirem o controle de suas vidas, enquanto minoria linguística, com potencial para busca de conhecimentos e ação crítica, transformando suas realidades.

Durante essa atividade, constatamos que o diálogo amplia conhecimentos e favorece a criticidade, e que o empoderamento se dá no coletivo, onde na e com a interação, os sujeitos podem conhecer e refletir melhor sobre sua realidade e reconhecer a necessidade de ação para transformá-la.

$\mathrm{Na}$ interação com o outro, os adolescentes demonstraram o sentimento de pertencimento a um grupo minoritário, usuário da Língua Brasileira de Sinais, questionando o direito de se comunicarem em todas as esferas da sociedade, mais especificamente, na área da saúde. Esses adolescentes identificaram os problemas vividos e, coletivamente, começaram a propor soluções como - a mais defendida por todos eles - que os trabalhadores da saúde deveriam aprender Libras.

$\mathrm{Na}$ última roda dialógica, os três temas abordados foram retomados por meio de uma reflexão individual e coletiva, em que cada sujeito pôde socializar a ampliação de seus conhecimentos, que ocorreu por meio de práticas dialógicas referentes ao autoconhecimento, à saúde e ao seu autocuidado e à tomada de consciência nas práticas diárias para o cuidado de si. Evidenciamos, assim, uma postura crítica frente aos problemas vivenciados, bem como a busca pela superação utilizando reflexões e diálogos, presentes em uma postura ativa com aprendizagens significativas.

\section{Considerações finais}

Podemos afirmar que a pesquisa-ação favoreceu a abordagem da Educação para a Saúde junto aos adolescentes surdos, durante as Rodas Dialógicas, estimulando o autoconhecimento, a construção de conceitos, a reflexão, a conscientização e o empoderamento; pois evidenciamos a (re)construção dos conhecimentos dos participantes quanto ao autocuidado.

No que tange ao autocuidado, utilizando um contexto significativo, por meio do diálogo em LS, em contato individual e coletivo com os conhecimentos prévios e os novos saberes adquiridos na roda, vivenciamos momentos de reflexão que permitiram a cada adolescente surdo despertar para o autocuidado. Entende-se, dessa forma, que foi dado o primeiro passo na superação da condição de meros receptores, para serem sujeitos ativos e críticos no cuidar de si, como verificado na quarta roda, onde enunciaram entender as ações que antes cumpriam sem refletir sobre ela; além do despertar para romper a passividade frente ao cuidado em saúde, assumindo a responsabilidade pela busca de melhor qualidade de vida.

Constatamos, assim, a necessidade de a Língua de Sinais estar presente em todas as áreas da sociedade, oferecendo condições para interação, trocas dialógicas, desenvolvimento da consciência crítica, enfim, para um desenvolvimento global da pessoa surda. Há que se considerar os fatores de subjetividade, as realidades socioculturais e as questões políticas envolvidas nesse processo. 
Educação para saúde por meio de processos dialógicos e o autocuidado ...

Neste estudo, partimos dos conhecimentos prévios, valorizando as experiências de cada adolescente, utilizando uma abordagem de construção coletiva do saber. Com os resultados das Rodas Dialógicas, novas significações foram produzidas para as ações de autocuidado e atentamos para uma nova forma de olhar e sentir o "ser" surdo em uma comunidade prioritariamente ouvinte, pontuando, dessa maneira, que as pessoas surdas, tendo suas singularidades linguísticas valorizadas, também são seres humanos capazes de efetivarem esse processo.

Ao retomarmos as questões da entrevista, verificamos que os processos dialógicos favoreceram o entendimento para o autocuidado agregando conhecimento e reflexão frente ao cuidar de si de maneira integral e não apenas a preocupação com o físico, considerando as dimensões emocional, social, mental e espiritual, nos âmbitos individual e coletivo.

Podemos anunciar a necessidade de uma educação dialógica e ativa por toda a vida, em todos os espaços, em destaque nesta pesquisa, nos espaços escolares e de saúde, oferecendo condições para que as pessoas surdas participem ativamente da sociedade, como sujeitos que possuem direitos e deveres; estimulando o autoconhecimento, o conhecimento da realidade e o sentimento de pertencimento à sociedade, atuando nela e, consequentemente, vencendo o isolamento imposto pelas barreiras de comunicação.

Em síntese, as Rodas Dialógicas possibilitaram aos adolescentes surdos inter(agirem) utilizando a Língua Brasileira de Sinais, a refletirem sobre suas vivências e os significados da mudança, no status e na prática, de receptores a construtores de conhecimentos para o autocuidado. Reiteramos a necessidade da mobilização para a busca de novas práticas, novos fazeres visando à formação de cidadãos autônomos e responsáveis por sua saúde, com vistas ao aumento da qualidade de vida e de serviços educacionais ofertados às pessoas surdas, bem como agregar conhecimentos aos já construídos no campo da Educação em Saúde, na perspectiva de uma sociedade inclusiva.

\section{Referências}

BRANDÃO, C. R. O que é método Paulo Freire. São Paulo: Brasiliense, 1981.

BRASIL. Secretaria de Educação Fundamental. Parâmetros curriculares nacionais: meio ambiente, saúde. Brasília, 1997.

. Lei $\mathbf{n}^{\mathbf{0}}$ 10.436, abril de 2002. Dispõe sobre a Língua Brasileira de Sinais - Libras e dá outras providências. Disponível em: <http://www.planalto.gov.br/ccivil_03/LEIS/2002/ L10436.htm>. Acesso em: 10 jun. 2011.

. Decreto $\mathbf{n}^{\circ} \mathbf{5 . 6 2 6}$, de dezembro de 2005. Regulamenta a Lei n 10.436, de 24 de abril de 2002 e o artigo 18 da Lei n 10.098 de 19 de dezembro de 2000. Disponível em: < http:/ / www.planalto.gov.br/ccivil_03/_Ato2004-2006/2005/Decreto/D5626.htm>. Acesso em: 10 jun. 2011.

BUB, M. B. C. et al. A noção de cuidado de si mesmo e o conceito de autocuidado na enfermagem. Texto \& Contexto e Enfermagem, Florianópolis, v. 15, p. 152-157, 2006. 
BUENO, S. M. V. Educação preventiva em sexualidade, DST - aids e drogas nas escolas -pesquisa-ação e o compromisso social. 2001. 263 f. Tese (Livre-docência) Escola de Enfermagem, Universidade de São Paulo, Ribeirão Preto, 2001.

CAMARGO-BORGES, C.; JAPUR, M. Sobre a (não) adesão ao tratamento: ampliando sentidos do autocuidado. Texto \& Contexto em Enfermagem, Florianópolis, v. 17, n. 1, p. 64-71, 2008.

CHAVEIRO, N. Qualidade de vida das pessoas surdas que se comunicam pela língua de sinais: construção da versão em libras dos instrumentos WHOQOL-BREF e WHOQOL-DIS. 2011. 252 f. Tese (Doutorado em Ciências da Saúde) - Faculdade de Medicina, Universidade Federal de Goiás, Goiânia, 2011.

FERNANDES, E. Linguagem e surdez. Porto Alegre: Artmed, 2003.

FREIRE, P. Pedagogia da autonomia: saberes necessários à prática educativa. São Paulo: Paz e Terra, 1996.

Terra, 2014a.

Pedagogia da indignação: cartas pedagógicas e outros escritos. São Paulo: Paz e

Pedagogia do oprimido. Rio de Janeiro: Paz e Terra, 2014b.

FREIRE, P.; SHOR, I. Medo e ousadia: o cotidiano do professor. Rio de Janeiro: Paz e Terra, 1986.

HOROCHOVSKI, R. R.; MEIRELLES, G. Problematizando o conceito de empoderamento. In: SEMINÁRIO NACIONAL MOVIMENTOS SOCIAIS, PARTICIPAÇÃO E

DEMOCRACIA, 2., 2007. Florianópolis. Anais... Florianópolis: UFSC, 2007. p. 485-506.

LACERDA, C. B. F. O intérprete de língua de sinais no contexto de uma sala de aula de alunos ouvintes: problematizando a questão. In: LACERDA, C. B. F.; GÓES, M. C. R. (Org.). Surdez: processo educativo e subjetividade. São Paulo: Lovise, 2000. p. 7-32.

. Intérprete de Libras: em atuação na educação infantil e no ensino fundamental. Porto Alegre: Mediação; São Paulo: Fapesp, 2009.

LACERDA, C. B. F; ALBRES, N. A.; DRAGO, S. L. S. Política para uma educação bilíngue e inclusiva a alunos surdos no município de São Paulo. Educação e Pesquisa, São Paulo, v. 39, n. 1, p. 65-80, jan./mar. 2013.

PELICIONI, M. C. F.; PELICIONI, A. F. Educação ambiental, promoção da saúde e pesquisa-ação: um diálogo possível? In: TOLEDO, R. F.; JACOBI, P. R. A pesquisaação na interface saúde, educação e ambiente: princípios, desafios e experiências interdisciplinares. São Paulo: Annablume, 2012.

PERLIN, G. T. T. Cultura e educação bilíngue no pulsar das identidades surdas contemporâneas. In: WITKOSKI, S. A.; FILIETAZ, M. R. P. (Org.). Educação de surdos em debate. Curitiba: UTFPR, 2014. p. 223-232.

SACKS, O. W. Vendo vozes: uma viagem ao mundo dos surdos. São Paulo: Companhia das Letras, 1998. 
SANTANA, A. P. Surdez e linguagem: aspectos e implicações neurológicas. São Paulo: Plexus, 2007.

THIOLLENT, M. Fundamentos e desafios da pesquisa-ação: contribuições na produção de conhecimentos interdisciplinares. In: TOLEDO, R. F; JACOBI, P. R. (Org.). A pesquisaação na interface da saúde, educação e ambiente. São Paulo: Annablume, 2012. 